\title{
Business Model Canvas as Tool for SME
}

\author{
Jan Frick and Murshid Mikael Ali \\ University of Stavanger, Norway \\ http: / /www. uis.no
}

\begin{abstract}
SME needs good tools to overcome the "grow or die" situation many of them reaches a few years after start. This paper describes the strategy of two SMEs, based on a short case study, in the context of Osterwalders' Business Model Canvas. The investigation try to map whether SMEs, such as the given case studies, actually follow or can utilize a pattern towards success in line with Osterwalders Business Map Canvas. , The work suggests that the Canvas is suitable for mapping purposes of current activities, but not suitable as a "paradigm" or framework to follow when outlining strategies for the future.
\end{abstract}

Keywords: Business models, innovation, business model canvas, case studies.

\section{Introduction}

SME companies tend to be less concerned about strategy and long-term development and more concerned on how to survive today. They seem to come to a stage where they either die or change to improved growth. How fast this stage arrives depends on type of industry and several external and internal factors. There are various business models and strategy tools that aim to map and describe how companies should run and develop their operations.

In general the purpose of creating a model is to help understand, describe, or predict how things work in the real world by exploring a simplified representation. How a business model can be developed and used to explain and communicate strategy for a company has changed a lot during the last 30 years. (Dodgson, Gann, \& Salter, 2008; Gertsen, Acur, Sun, \& Frick, 2002 ; Laugen \& Frick, 2002) And if we can see a trend, it is that start-ups develop such descriptions in their business plans, and larger companies sets these methods into a system when they debate how to proceed and develop into new products, new markets etc.

Morten Lund presented a paper at APMS-2012 where he utilized the canvas developed for Business Models by Osterwalder to tell a story for companies on what could be their strategy.(Lund, 2012)

\subsection{Osterwalders' Business Model Canvas}

Osterwalder (Osterwalder \& Pigneur, 2011) have developed and published a one-page strategy or business plan model. The content of this one is not a new approach as the topics are the same as most entrepreneurship literature suggest as content for a start-up company business plan. 


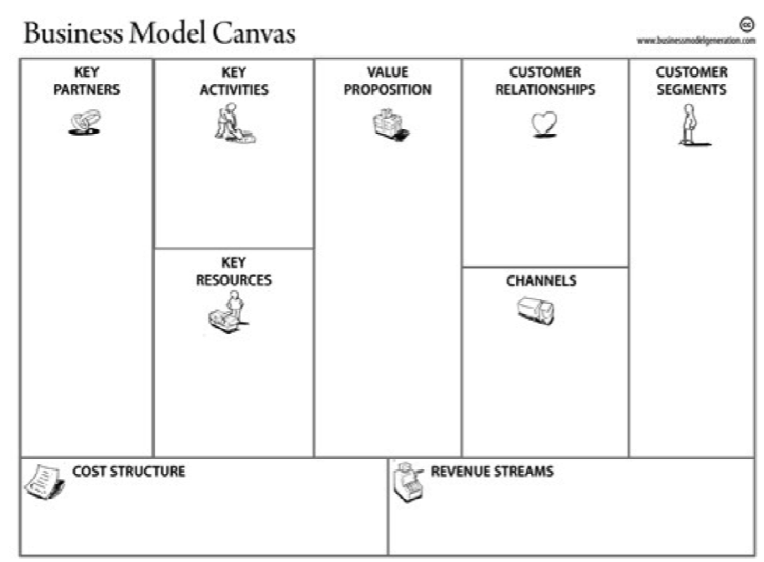

Fig. 1. A simple version of Osterwalders Business Model Canvas

The approach differs from the former issues in terms that it insists on a one-page document. The main reason for this is that a main purpose is to communicate and implement the strategy described by the business model. The other issue is that Osterwalder advise to use as much graphical icons in the one page business plan as possible. This is recommended to get people to think, and also create as much of a visual one-page impression as possible. Morten Lund in his APMS-2012 paper (Lund, 2012) took this even further and emphasized that the canvas should be a storytelling. He even used video clips as pieces in this storytelling context.

The authors of this paper have a similar experience from former projects where we used video-clips, gaming, or system dynamic models to tell a story or parts of a story. In our case this was sometimes done in a strategy context but mostly in an organizational learning context. (J. Frick \& Riis, 1991; Jan Frick, 2001; Riis, 1978)

\section{Case Companies}

These case studies are done to understand the correlation new technology companies might have with Osterwalders' Business model canvas, and its relevance for such entities. Both cases are based on longitudinal, qualitative case study over a period of more than a year of both companies Sekal AS, and 2K Tools AS. The companies were closely followed, from their first commercialization period (to the local market) and then further on towards internationalization of their products and services.

The longitudinal studies of both companies were a part of a commercialization project towards Saudi-Arabia, where researcher(s) followed the companies from start, which involved meetings with clients, and partners, till actual sales in foreign countries, this involved dialogue with the management of the different companies, such as the CEO, CFO, founders and board members, in addition to correspondence and feedback from potential customers and clients in different countries in the Middle East. Both companies have arrived at a stage where they are in need of development. 


\subsection{Sekal AS}

Sekal AS is a technology company based in Stavanger, Norway. The company is a result of a merger between Drilltronics AS and Drill Scene AS. Both of the latter companies were established in 2004. The technology that lays the foundation for these companies has been developed for several years.

The products are classified as drilling technology for offshore and onshore oil sector, and allow users to analyze, detect and solve problems during drilling. Patented, and advanced mathematical models implemented and calculated in real-time, makes this possible. This technology provides a much more efficient and safer drilling process that also gives you more control over the well and the capability to prevent accidents much earlier. The technology is sold in the North Sea area, and Sekal intend to expand to international markets worldwide. Sekal AS has an office in Houston in addition to their office in Stavanger, Norway. They are also in a process of establishing an office in the GCC region to serve the large market in the Middle East.

Sekal AS has several leading oil companies as clients, and has recently signed agreements with Statoil and other major stakeholders on the use of its technology. Other customers of the company include: Schlumberger, BP, Statoil, ConocoPhillips and Dong Energy. They have also received interest from oil companies around the world who are very interested in the technology, including Saudi Aramco.

\section{$2.2 \quad 2 \mathrm{~K}$ Tools AS}

$2 \mathrm{~K}$ Tools AS is an innovative engineering company that provides new drilling technology to the oil and gas industry. Two engineers with several years experience from other companies founded the company in 2006. They have in the past year focused on the commercialization of new technology in drilling and have as a result of this patented system "Drill String Internal Wiper" or DSIWS.

DSIWS is a tool used in wells during drilling, and drilling companies that provide significant savings due to increased safety on the platforms. The system is based on many years of experience in the oil industry, and has been tested with good results. The company is now in "the tipping point" in relation to the commercialization of its product internationally, and is the first company that can deliver this type of equipment. In 2011 the company commercialized the DSIWS in the North Sea and has started to gain revenue from deliveries of the technology to mainly ConocoPhillips. $2 \mathrm{~K}$ Tools expects to reach $\$ 1$ million in revenue in 2011 , due to new projects both nationally and internationally, and are aiming to triple sales in the coming years. $2 \mathrm{~K}$ Tools is a small company, with currently only three employees.

$2 \mathrm{~K}$ Tools has attracted investments from external sources of 9 million NOK. Which allow for improvements of DSIWS, development of other technology and the international expansion of the company. The main owners of the company are large Venture Capitalist funds. The company sees oil fields onshore in the Middle East, and then in particular Saudi Arabia, which is ideal in terms of their product. 


\section{Analysis}

How does these two cases fit to the Business Model Canvas? In both cases the companies were established related to a key activity that was drilling for petroleum in the North Sea, and close relations were key partners, which in these cases also partly were customers.

\subsection{Key Activities}

2K Tools AS has a mechanical and a physical innovation, which needs storage, shipping and logistics. The company has developed innovative tools that reduce mud spills on platform, and increase HMS for the employees. The tool is a cleaning device that is dropped into the drill hole and retracted again. The tool does not need a high degree of expertise, and can be learned easily by personnel on the platforms.

Sekal AS sells and implements software solutions, that are highly sensitive for oil operators. The technology is a real time detection of problems that might occur in wells that are being drilled. This will help drilling operators to cut costs and increase their HMS. The technology is named DrillScene and has been developed for the past twenty years at the IRIS-research center in Stavanger, Norway. This product is highly scalable, and has no costs related to logistics and storage.

\subsection{Key Resources}

$2 \mathrm{~K}$ Tools is still run by their founders, and is backed up by large Venture Capitalists, that has a interest in commercializing and selling the company in a short period of time. Being a small company, run by their founders, they have flexibility, but it is also restricted to approval from the Venture Capitalists when it comes to larger strategic decisions. Their key resources are their founders and the management that makes most decisions related to the company and its survival.

Sekal AS is in a similar situation but the entrepreneur or founders do not run the company. The owners have hired in a professional management that has long experience in commercializing similar ventures. Their technology has been through the "bleeding" period, and developed and ready to be commercialized into the market. Their Key Resources now are the sales and marketing team, and their IT engineers that improve the product.

\subsection{Value Proposition}

$2 \mathrm{~K}$ Tools AS value proposition is that the new Wiper Technology that has been developed increases HMS safety on offshore platforms. This is due to the reduction in mud spill once the drill pipe has been retracted to the platform.

Sekal has a similar value proposition. Their technology allows the drilling company to detect and solve problems that might happen in the well during a drilling process. This will also increase HMS for the drilling contractor, but also help them reduce costs, because shut down due to production pauses are very expensive. 


\subsection{Channels}

$2 \mathrm{~K}$ Tools are still in a process where they are evaluating their business model, and channels towards their customers. The company is still quite small, and is in need for agents or operators in foreign countries, in order to serve and deliver the service that they are supposed to do. Their strategy has therefore been to ally with an agent or a partner that can provide the necessary infrastructure to deliver their technology.

Sekal has a technology that requires insight and knowledge about the product. As complex software it needs to be handled by experts from the Sekal team. Therefore the company always works directly with their end-client, which in every case is the drilling operator, such as Statoil and Petrobras. Sekal sets up the infrastructure and the technology, and also leads the operations for the client.

\subsection{Cost Structure}

The technology that $2 \mathrm{~K}$ Tools deliver is a physical cleaning device that needs to be produced, and handled by personnel on a platform. The tool is currently being produced in Narvik, Norway and from there shipped abroad to other countries. Later on, it is required that the tool receives maintenance by the agent or operator that has rented the tool.

As a software company, Sekal has a highly scalable product. Once developed, and implemented into the clients portfolio, Sekal can run operations over time with high margins and lower maintenance costs. However there are certain costs involved in adapting each system to specific wells, and also setting up a infrastructure at the clients premises.

\subsection{Revenue Stream}

2K Tools business model has been based on a rental structure. The company wish to rent out their equipment to agents and operators in the oil industry that wants to use the technology to increase HMS at their platforms. Their margins are high in the North Sea, due to the general level of payment in the region. However, in foreign countries with lower wages and income, they face a challenge in terms of margins on their products. $2 \mathrm{~K}$ Tools has therefore also evaluated the possibility of starting production of their tools in a foreign, low cost country.

Sekal receives their income from end clients and drilling operators that engage in long term contract with the company. For example, Sekal recently signed a major deal with Statoil, giving them a frame-contract over five years for supplying Statoil with their technology. This frame-contract gives Sekal a reliable source of income for several years while they try to find other clients that would like to use their technology. Since the company has been through the "bleeding" period, one contract with a major client is sufficient to run a sustainable company that makes profit and has enough resources for expansion. 


\section{Discussion}

Osterwalders Business Model Canvas gives us an overview of how the companies operate and how their current strategies are outlined. It therefore is a great tool to be used, for example in internal discussions about maximizing revenues, or improving things such as customer relations. In the cases of both case companies, they operate in a very changing environment where the best strategy for each company needs to be outlined by the management at an ad-hoc basis.

For example, assessing the revenue channels through Osterwalders shows us that $2 \mathrm{~K}$ Tools have a rental model that is viable in the North Sea due to higher margins and better conditions in terms of payment. But when the company looks at emerging markets, it needs to review its initial penetration strategy in order to be competitive. Lower margins and a different mental mind-set from the customer side in other markets will not allow $2 \mathrm{~K}$ Tools to implement the same strategy used in the North Sea, in for example the Middle East. We know this because when $2 \mathrm{~K}$ Tools offered their services to major Arab companies, they were turned down due to their high price asking (which was influenced by the fact that they could receive this amount in the North Sea). The Middle Eastern market did not find the price/ beneficial ratio to be as high as their North Sea counterparts. So in order to penetrate this market, the company and its management decided to revise and totally change their business model for this particular market. Alas, the strategy chosen follows practical need to adapt to new market conditions/ differences.

This is just one of many examples where the company needs to be strategic and flexible when making decisions during international expansion. Using Osterwalders model in this case would be more or less useless, as it would be altered for every market, or every customer/ client differences.

Sekal's income model is different as it is highly scalable, and quite adaptive from market to market. Sekal's income is derived from already developed software, which has low costs when implemented in new markets or at new clients. They usually sign long term agreements with clients, and have business model that has been proven suitable for several markets, despite the differences in payment conditions and margins. This is mostly due to the fact that Sekal has a niche, and a highly advanced technology that only their team, or others that has received sufficient training, can handle the operations. Here, their strategy would suit in a Business Model Canvas, and set as an example to follow.

However, the need for flexible strategy arises at Sekal when you look at the channels for distribution of the technology. The reason for this is because many countries around the world have different rules and regulations for doing business. When Sekal looked at the market in Saudi Arabia, the company needed to partner up with a local firm in order to be able to bid towards Saudi Aramco. The local market conditions also gave them several options, such as choosing to partner with a agent, go into a Joint-Venture or establishing themselves in a so-called "free-zone", with more or less $100 \%$ ownership. All of these options had their pros and con's and knowing which one of them that would be perfectly suited for Sekal is quite difficult to assess. In the end the company ended up with an agent option, with the possibility to develop the 
cooperation into a JV, and then in the long run maybe buy out the local counterpart (if operations were successful). This allowed the company to choose an optimizing strategy specially designed for the Saudi-Arabian market, and some other markets in the Middle East.

This strategy has direct implications into Sekal's revenue streams in the SaudiArabian market, since the agent structure obliges the company to pay out a commission of 5-7\% of their revenues to the local partner, with a gradual increase if the company forms a JV, then a gradual decrease then Sekal buys into the JV and ultimately acquires the whole operation in Saudi-Arabia. This case shows that Sekal needs to be highly flexible when making decisions related to distribution channels, and might have two totally different strategies in different countries. Putting this into an Osterwalders model would prove to be difficult.

\section{Conclusion}

From the description and analysis we see that the cases in some ways can fit into the canvas. However, we are not able to make as neat picture for the companies as recommended by Osterwalders. This may be due to missing information or a lack of understanding, but it may just as much be due to a complex daily business and complex relation to partners and customers at the companies. If both $2 \mathrm{~K}$ Tools and Sekal had been in a starting phase, where management or founders need to have a business plan to stick to, they would have had great use of the Osterwalders Business Canvas Model. It is because the model provides a solid framework, which small start-ups can work from.

However, both $2 \mathrm{~K}$ Tools and Sekal are companies that have developed into a stage where they already have commercialized their products, and are looking into different ways to increase revenues and improve their infrastructure. This makes them flexible in their strategies when for example penetrating new markets, and increasing their business. This also leaves a large part of the strategy decisions in the hand of the management, and is taken more or less on case-by-case basis, as we have shown in our analysis.

It is impossible for both companies, taken in account that they both wish to operate in international markets, to pursue one strategy either it is revenue stream or source of marketing. The complex nature of this makes the Osterwalders Canvas Tool suitable for both $2 \mathrm{~K}$ Tools and Sekal when mapping their current structure into a "viewable" and simple story that they can use for example learning purposes. A conclusion would somewhat say that the Osterwalders model, with our two case-studies, is suitable for mapping purposes of current activities, but not suitable as a "paradigm" or framework to follow when outlining strategies for the future.

Seen from outside both companies are doing business in a complex infrastructure with many players, and therefore it is hard to make a good and simple story from what they are doing. And even more, it is our firm belief that they will need to restructure into a "simpler story" of partner relations (Lund, 2012) and activities if they are to succeed when moving abroad. 


\section{References}

1. Dodgson, M., Gann, D.M., Salter, A.: The management of technological innovation strategy and practice, Revised edn. Oxford University Press, Oxford (2008)

2. Frick, J., Riis, J.O.: Organizational Learning as a Means for achieving both Integrated and Decentralized Production Systems. Paper presented at the Computer Application In Production Engineering, Bordeaux (1991)

3. Frick, J.: Emerging of a Model for Vocational Training. Paper presented at the 4th SMESME International Conference on Stimulating Manufacturing Excellence in Small and medium Enterprises, Aalborg, May 14-16 (2001)

4. Gertsen, F., Acur, N., Sun, H., Frick, J.: Formal manufacturing strategy - does it matter? Paper Presented at the Euroma 2002, København, June 4 (2002)

5. Laugen, B.T., Frick, J.: Linking of strategy and supply chain management: change management or opportunity driven development. Paper Presented at the Euroma 2002, København, June 4 (2002)

6. Lund, M.: Innovating a business model for services with storytelling. Paper Presented at the Advances in Production Management Systems 2012, Rhodos, Greece (2012)

7. Osterwalder, A., Pigneur, Y.: Business model generation a handbook for visionaries, game changers, and challengers. Wiley-Blackwell, Hoboken (2011)

8. Riis, J.O.: Design of management systems: an analytical framework. Akademisk Forlag, Copenhagen (1978) [eksp. DBK] 